\title{
LO COTIDIANO Y LO RELIGIOSO EN EL MUNDO GRÁFICO PALEOLÍTICO
}

\section{DAILY AND RELIGIOUS IN THE GRAPHIC PALEOLITHIC WORLD}

\author{
Rodrigo de Balbín-Behrmann y José Javier Alcolea-GonzÁlez \\ Universidad de Alcalá \\ babubera@movistar.es \\ ORCID: 0000-0002-3947-5308 \\ jjavieralcolea@gmail.es \\ ORCID: 0000-0003-3902-7713
}

DOI: $10.1387 /$ veleia.18071

Resumen: Establecemos por costumbre una diferencia funcional entre lo cotidiano y lo religioso en el comportamiento de la humanidad paleolítica, y eso no es más que un artificio actualista. Distinguimos ambas formas que son parte de un solo comportamiento humano, como expresión de una conducta con variantes. Intentamos aquí reflexionar sobre la ausencia de espacios dedicados de manera exclusiva al comportamiento religioso, hecho contrastado por la existencia de las manifestaciones gráficas rupestres al aire libre.

Palabras clave: comportamiento paleolítico, religión y espacio, cuevas y arte al aire libre.

Abstract: The usual assumption of a functional difference between daily and religious aspects in the behavior of Paleolithic humanity is probably a transposition of a modern conception. Both should be taken as different manners of expressing the same human behavior. On the basis of the existence of open air art manifestations, this paper suggests that, in the Palaeolithic world, there were no spaces dedicated exclusively to religious issues.

Keywords: Paleolithic behavior, religion and space, caves and open air art.

Recibido: 16-02-2017

Informado: 29-03-2017

Definitivo: 19-04-2017

\section{INTRODUCCIÓN}

Muchas cosas hay en el comportamiento prehistórico que no podemos resolver directamente con la metodología arqueológica, y entre ellas una parte importante de lo que se refiere a las creencias, a lo ritual y a lo potencialmente religioso.

Llamamos cotidiano a lo que forma parte del comportamiento habitual del grupo, a lo que se hace todos los días porque está inscrito en el modo cultural humano y le permite sobrevivir y perpetuarse. En ese capítulo solemos incluir lo que se relaciona con la alimentación, la obtención de recursos, la fabricación de los útiles y la organización de la morada. Segregamos sin embargo todo 
aquello que consideramos menos inmediato y funcional, aquello que puede relacionarse más directamente con el pensamiento, la ritualidad o los fundamentos sociales.

No deja de ser sorprendente que entendamos como cotidiana la fabricación de un útil y no el pensamiento que subyace a ella, o la propia necesidad generada por el grupo que la provoca. Cotidiano debe ser todo lo que se practica asiduamente, y el símbolo y la grafía acompañan la conducta humana lo mismo que los gestos técnicos materiales.

Definimos como material lo inmediato, tangible y medible como objeto, y pretendemos que ello se refiera solamente a los artefactos móviles que sirven para la obtención económica. Las formas gráficas son tan materiales como los artefactos, tanto que muchas veces son variantes artefactuales que se dotan de algún aditamento diferencial. Pero las paredes son también soportes materiales de imágenes materiales, tangibles y medibles, en dos o tres dimensiones. El hecho de que esas imágenes sean vehículo de ideas o consecuencia de las mismas no las hace diferentes de los artefactos útiles, que también son consecuencia de las ideas de un grupo, de su tradición cultural y de la resolución de sus problemas. En este último caso el contenido ulterior de los objetos sería diferente en principio de aquél que poseen las imágenes, pero derivaría también de la ideología grupal y sería por tanto producto de aquello que el conjunto social plasma en los objetos de utilidad inmediata o mediata.

La tradición investigadora establece también una dicotomía artificial entre las representaciones gráficas móviles y rupestres, cuando los sintagmas representados en ambos soportes son fundamentalmente los mismos. Hacemos una categoría académica para las representaciones rupestres y otra de valor doméstico para las muebles, dentro de un ámbito que contiene a las dos por igual. Es evidente que las formas rupestres resultan más visibles y monumentales que las muebles, al menos generalmente, porque no siempre sucede así. Sin embargo ambas forman parte del mismo principio conceptual y del mismo bagaje cultural, y se encuentran en idéntico espacio topográfico, como ya indicamos en trabajos anteriores (Balbín-Behrmann y Alcolea-González 1999, 2005). Las grafías rupestres no requieren un sitio diferente para su plasmación, que al ser ritual o religioso debería estar segregado de los demás, si lo que allí se hiciera tuviera un carácter diferente al que engloba todas las demás manifestaciones conductuales del grupo.

Cuando hace casi dos décadas reflexionábamos sobre el significado de las grafías paleolíticas europeas, ya advertimos (Balbín-Behrmann y Alcolea-González 1999) sobre una realidad que había sido frecuentemente minusvalorada, la recurrente asociación entre zonas de habitación y decoraciones rupestres. Esta coincidencia física incluía en no pocas ocasiones la contemporaneidad genérica entre ambos fenómenos, lo que en esos casos debía ser interpretado como prueba de la inclusión de las grafías dentro de la esfera de lo cotidiano, desmintiendo la exclusiva significación religiosa que se les había adjudicado tradicionalmente. Una primera recapitulación sobre los sitios más significativos en los que se verifica la asociación topográfica y cronológica de lo rupestre y lo supuestamente doméstico (tabla 1) muestra a las claras que estamos ante una realidad bastante habitual durante el Paleolítico Superior.

Las posibilidades de analizar pormenorizadamente este tipo de asociaciones son múltiples, habida cuenta de la propia diversidad de los hábitats superopaleolíticos y sus variables estacionales, funcionales o logísticas, y de las múltiples formas que el mensaje gráfico paleolítico puede adoptar. Las formas que adoptan esas asociaciones pueden ser variadas a lo largo del tiempo, según predomine un tipo u otro de establecimiento y de ocupación más o menos interna de la cueva, pero la cercanía entre ambas formas de conducta es reiterada a lo largo del tiempo, en las cuevas y fuera de ellas. 


\begin{tabular}{|c|c|c|c|c|c|c|c|c|}
\hline YACIMIENTo & $\begin{array}{l}\text { LOCALIZACIÓN } \\
\text { GEográfica }\end{array}$ & $\begin{array}{c}\text { Tipo } \\
\text { YACIMIENTO }\end{array}$ & $\begin{array}{c}\text { EDAD } \\
\text { HÁbitat PS }\end{array}$ & CONJUNTO GRÁFico & Cronología grafías & $\begin{array}{c}\text { Zona de } \\
\text { ASOCIACIÓN } \\
\text { H-G }\end{array}$ & $\begin{array}{c}\text { Cronología } \\
\text { Asociación H-G }\end{array}$ & BiLBIOGRAFía \\
\hline Farizeu & $\begin{array}{l}\text { Côa- } \\
\text { Portugal }\end{array}$ & Aire libre & S-M & Grabados & E II (G-S) & Exterior & ¿G?-S & $\begin{array}{l}\text { Aubry y Sampaio } \\
2008\end{array}$ \\
\hline $\begin{array}{l}\text { Gorham's } \\
\text { Cave }\end{array}$ & Gibraltar & Cuieva & S-M & $\begin{array}{l}\text { Pinturas y } \\
\text { grabados }\end{array}$ & E IV (M) & Interior & M & Balbín et al. 1999 \\
\hline $\begin{array}{l}\text { Cueva } \\
\text { Ambrosio }\end{array}$ & $\begin{array}{l}\text { Almería- } \\
\text { Levante }\end{array}$ & Cueva & $S$ & $\begin{array}{l}\text { Pinturas y } \\
\text { grabados }\end{array}$ & E III (s) & Exterior & S & Ripoll y Muńoz 2014 \\
\hline Parpalló & $\begin{array}{l}\text { Valencia- } \\
\text { Levante }\end{array}$ & Cueva & G-S-M & Grabado & E II (G) & Interior & G & $\begin{array}{l}\text { Aura y Villaverde } \\
2014\end{array}$ \\
\hline $\begin{array}{l}\text { Fuente } \\
\text { del Trucho }\end{array}$ & $\begin{array}{l}\text { Huesca- } \\
\text { Pirineos }\end{array}$ & Cueva & G-S & $\begin{array}{l}\text { Pinturas y } \\
\text { grabados }\end{array}$ & E II-(G) & Interior & G & Utrilla et al. 2014 \\
\hline $\begin{array}{l}\text { Abrigo de } \\
\text { La Viña }\end{array}$ & $\begin{array}{l}\text { Asturias- } \\
\text { Cantábrico }\end{array}$ & Abrigo & A-G-S-M & Grabados & E I-II (A-G) & Exterior & A-G & $\begin{array}{l}\text { Barandiarán y García- } \\
\text { Diez } 2007\end{array}$ \\
\hline La Lluera I & $\begin{array}{l}\text { Asturias- } \\
\text { Cantábrico }\end{array}$ & Cueva & S-M & Grabados & E II (G-S) & $\begin{array}{l}\text { Exterior- } \\
\text { semiexterior }\end{array}$ & ¿G?-S & Fortea 1989 \\
\hline Las Caldas & $\begin{array}{l}\text { Asturias- } \\
\text { Cantábrico }\end{array}$ & Cueva & S-M & Grabados & E I-II (G-S) & Semiexterior & $S$ & Corchón et al. 2009 \\
\hline $\begin{array}{l}\text { Cueva } \\
\text { del Conde }\end{array}$ & $\begin{array}{l}\text { Asturias- } \\
\text { Cantábrico }\end{array}$ & Cueva & A & Grabados & E I (A) & Exterior & A & Fernández et al. 2005 \\
\hline Coimbre & $\begin{array}{l}\text { Asturias- } \\
\text { Cantábrico }\end{array}$ & Cueva & G-M & Grabados & E IV (M) & Semiexterior & M & $\begin{array}{l}\text { Álvarez-Alonso et al. } \\
2009\end{array}$ \\
\hline La Lloseta & $\begin{array}{l}\text { Asturias- } \\
\text { Cantábrico }\end{array}$ & Cueva & M & $\begin{array}{l}\text { Pinturas y } \\
\text { grabados }\end{array}$ & E II-III-IV (G-S-M) & Semiexterior & M & $\begin{array}{l}\text { Balbín-Behrmann et } \\
\text { al., } 2005\end{array}$ \\
\hline Tito Bustillo & $\begin{array}{l}\text { Asturias- } \\
\text { Cantábrico }\end{array}$ & Cueva & M y anterior & $\begin{array}{l}\text { Pinturas y } \\
\text { grabados }\end{array}$ & E I-II-III-IV (A-G-S-M) & $\begin{array}{l}\text { Semiexterior } \\
\text { e interior }\end{array}$ & M y prob. anterior & $\begin{array}{l}\text { Balbín-Behrmann et } \\
\text { al., } 2016\end{array}$ \\
\hline Llonín & $\begin{array}{l}\text { Asturias- } \\
\text { Cantábrico }\end{array}$ & Cueva & A-G-S-M & $\begin{array}{l}\text { Pinturas y } \\
\text { grabados }\end{array}$ & E II-III-IV (G-S-M) & Interior & ¿A?-G-S-M & $\begin{array}{l}\text { Fortea et al., 1995, } \\
2007\end{array}$ \\
\hline $\begin{array}{l}\text { Fuente del } \\
\text { Salín }\end{array}$ & $\begin{array}{l}\text { Cantabría, } \\
\text { Cantábrico }\end{array}$ & Cueva & G-S-M & Pinturas & E II $(G)$ & Semiexterior & G & $\begin{array}{l}\text { Moure et al., } \\
1984-85\end{array}$ \\
\hline $\begin{array}{l}\text { Hornos de } \\
\text { La Peńa }\end{array}$ & $\begin{array}{l}\text { Cantabría, } \\
\text { Cantábrico }\end{array}$ & Cueva & A-S-M & $\begin{array}{l}\text { Pinturas y } \\
\text { grabados }\end{array}$ & E I-II-IV (A-G-M) & Exterior & ¿A? & Gálvez y Cacho 2002 \\
\hline Altamira & $\begin{array}{l}\text { Cantabría, } \\
\text { Cantábrico }\end{array}$ & Cueva & G-S-M & $\begin{array}{l}\text { Pinturas y } \\
\text { grabados }\end{array}$ & E II-III-IV (A-G-S-M) & Semiexterior & G-S-M & $\begin{array}{l}\text { Heras y Lasheras } \\
2014\end{array}$ \\
\hline La Pasiega & $\begin{array}{l}\text { Cantabría, } \\
\text { Cantábrico }\end{array}$ & Cueva & S-M & $\begin{array}{l}\text { Pinturas y } \\
\text { grabados }\end{array}$ & E II-III-IV (G-S-M) & Semiexterior & S-M & $\begin{array}{l}\text { Balbín-Behrmann y } \\
\text { Glez.-Sainz } 1993\end{array}$ \\
\hline La Garma & $\begin{array}{l}\text { Cantabría, } \\
\text { Cantábrico }\end{array}$ & Cueva & M y anterior & $\begin{array}{l}\text { Pinturas y } \\
\text { grabados }\end{array}$ & E II-IV (A-G-M) & $\begin{array}{l}\text { Semiexterior } \\
\text { e interior }\end{array}$ & M y prob. anterior & $\begin{array}{l}\text { Arias y Ontañón } \\
2012\end{array}$ \\
\hline El Otero & $\begin{array}{l}\text { Cantabría, } \\
\text { Cantábrico }\end{array}$ & Cueva & M & Grabados & E IV (M) & Semiexterior & M & $\begin{array}{l}\text { González.-Sainz et al. } \\
1985\end{array}$ \\
\hline El Mirón & $\begin{array}{l}\text { Cantabría, } \\
\text { Cantábrico }\end{array}$ & Cueva & G-S-M & Grabados & E IV (M) & Semiexterior & M & $\begin{array}{l}\text { González-Morales y } \\
\text { Strauss } 2015\end{array}$ \\
\hline
\end{tabular}

Tabla I. Tabla-resumen de los principales yacimientos superopaleoliticos donde coinciden topográfica y cronológicamente dispositivos gráficos y restos de hábitat. (Abreviaturas: A-Aurinaciense, G-Gravetiense, S-Solutrense, Ep-Epigravetiense, M-Magdaleniense) 


\begin{tabular}{|c|c|c|c|c|c|c|c|c|}
\hline YACIMIENTo & $\begin{array}{l}\text { LoCALIZACIón } \\
\text { GEOGRÁFICA }\end{array}$ & $\begin{array}{c}\text { TIPO } \\
\text { YACIMIENTO }\end{array}$ & $\begin{array}{c}\text { EDAD } \\
\text { HÁBITAT PS }\end{array}$ & CONJUNTO GRÁFICO & Cronología grafías & $\begin{array}{c}\text { ZoNa DE } \\
\text { ASOCIACIÓN } \\
\text { H-G }\end{array}$ & $\begin{array}{c}\text { Cronología } \\
\text { asociación H-G }\end{array}$ & BiLbiografía \\
\hline La Haza & $\begin{array}{l}\text { Cantabría, } \\
\text { Cantábrico }\end{array}$ & Cueva & ¿S? & Pinturas & E II-III (G-S) & Semiexterior & ¿S? & Moure et al. 1991 \\
\hline $\begin{array}{l}\text { Venta de } \\
\text { la Perra }\end{array}$ & $\begin{array}{l}\text { Vizcaya, } \\
\text { Cantábrico }\end{array}$ & Cueva & ¿A-G? & Grabados & E I-II (A-G) & Exterior & ¿A-G? & $\begin{array}{l}\text { González-Sainz y San } \\
\text { Miguel } 2001\end{array}$ \\
\hline Askondo & $\begin{array}{l}\text { Vizcaya, } \\
\text { Cantábrico }\end{array}$ & Cueva & $A-G$ & $\begin{array}{l}\text { Pinturas y } \\
\text { grabados }\end{array}$ & E II (G) & Semiexterior & G & Gárate y Ríos 2012 \\
\hline Isturitz & $\begin{array}{l}\text { Pirineos- } \\
\text { Francia }\end{array}$ & Cueva & A-G-S-M & Bajorrelieves & E IV (M) & Semiexterior & M & Laplace 1984 \\
\hline Gargas & $\begin{array}{l}\text { Pirineos- } \\
\text { Francia }\end{array}$ & Cueva & $A-G$ & $\begin{array}{l}\text { Pinturas y } \\
\text { grabados }\end{array}$ & E II (A-G) & Semiexterior & G & Foucher et al. 2012 \\
\hline Pair-non-Pair & $\begin{array}{l}\text { Gironde- } \\
\text { Francia }\end{array}$ & Cueva & $A-G$ & Grabados & E II (A) & Semiexterior & A & Lenoir et al. 2006 \\
\hline Le Portel & $\begin{array}{l}\text { Ariège- } \\
\text { Francia }\end{array}$ & Cueva & M & $\begin{array}{l}\text { Pinturas y } \\
\text { grabados }\end{array}$ & E IV (M) & Interior & M & Vialou 1986 \\
\hline Fontanet & $\begin{array}{l}\text { Ariège- } \\
\text { Francia }\end{array}$ & Cueva & M & $\begin{array}{l}\text { Pinturas y } \\
\text { grabados }\end{array}$ & E IV (M) & $\begin{array}{l}\text { Sermiexterior } \\
\text { e interior }\end{array}$ & M & Vialou 1986 \\
\hline La Ferrasie & $\begin{array}{l}\text { Périgord- } \\
\text { Francia }\end{array}$ & Abrigo & $A-G$ & Pintura & E I (A) & Exterior & A & Delluc y Delluc 2015 \\
\hline Comarque & $\begin{array}{l}\text { Dordogne- } \\
\text { Francia }\end{array}$ & Cueva & M & $\begin{array}{l}\text { Grabado y } \\
\text { bajorrelieve }\end{array}$ & E IV (M) & Semiexterior & M & Delluc y Delluc 1984 \\
\hline Laugerie-Basse & $\begin{array}{l}\text { Dordogne- } \\
\text { Francia }\end{array}$ & Abrigo & M & $\begin{array}{l}\text { Pintura y } \\
\text { grabados }\end{array}$ & E IV (M) & Exterior & M & Roussot $1984 \mathrm{a}$ \\
\hline $\begin{array}{l}\text { L'Oreille } \\
\text { d'Enfer }\end{array}$ & $\begin{array}{l}\text { Dordogne- } \\
\text { Francia }\end{array}$ & Abrigo & G-S & $\begin{array}{l}\text { Pintura y } \\
\text { grabados }\end{array}$ & E II (G) & Exterior & 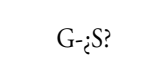 & Delluc y Delluc 2003 \\
\hline $\begin{array}{l}\text { Abri du } \\
\text { Poisson }\end{array}$ & $\begin{array}{l}\text { Dordogne- } \\
\text { Francia }\end{array}$ & Abrigo & $A-G$ & $\begin{array}{l}\text { Pintura, grabados } \\
\text { y bajorrelieve }\end{array}$ & E I-II (A-G) & Exterior & $A-G$ & Delluc y Delluc 2015 \\
\hline Abri Pataud & $\begin{array}{l}\text { Dordogne- } \\
\text { Francia }\end{array}$ & Abrigo & A-G-S & $\begin{array}{l}\text { Pintura y } \\
\text { grabados }\end{array}$ & E I-II (A-G) & Exterior & $\mathrm{A}-\dot{\zeta} \mathrm{G}$ ? & Chioti et al. 2007 \\
\hline $\begin{array}{l}\text { Abri } \\
\text { Vignaud- } \\
\text { Pataud }\end{array}$ & $\begin{array}{l}\text { Dordogne- } \\
\text { Francia }\end{array}$ & Abrigo & G & Pintura & E II $(G)$ & Exterior & G & Delluc y Delluc 2003 \\
\hline Abri de Laussel & $\begin{array}{l}\text { Dordogne- } \\
\text { Francia }\end{array}$ & Abrigo & A-G-S & $\begin{array}{l}\text { Pintura y } \\
\text { bajorrelieve }\end{array}$ & E II (G) & Exterior & G & Delluc y Delluc 2003 \\
\hline Abri Blanchard & $\begin{array}{l}\text { Dordogne- } \\
\text { Francia }\end{array}$ & Abrigo & A & Pintura & E I (A) & Exterior & A & Delluc y Delluc 2015 \\
\hline Abri Castanet & $\begin{array}{l}\text { Dordogne- } \\
\text { Francia }\end{array}$ & Abrigo & $\mathrm{A}$ & $\begin{array}{l}\text { Pintura y } \\
\text { grabados }\end{array}$ & E I (A) & Exterior & A & Delluc y Delluc 2015 \\
\hline Abri Labatut & $\begin{array}{l}\text { Dordogne- } \\
\text { Francia }\end{array}$ & Abrigo & G-S & $\begin{array}{l}\text { Pintura y } \\
\text { grabados }\end{array}$ & E II (G) & Exterior & G & Delluc y Delluc 2015 \\
\hline
\end{tabular}

TABLA I. (continuación) 


\begin{tabular}{|c|c|c|c|c|c|c|c|c|}
\hline YACIMIENTO & $\begin{array}{l}\text { LOCALIZACIÓN } \\
\text { GEOGRÁFICA }\end{array}$ & $\begin{array}{c}\text { TIPo } \\
\text { YACIMIENTO }\end{array}$ & $\begin{array}{c}\text { EDAD } \\
\text { HÁBITAT PS }\end{array}$ & Conjunto gráfico & Cronología grafías & $\begin{array}{c}\text { ZoNa DE } \\
\text { ASOCIACIÓN } \\
\text { H-G }\end{array}$ & $\begin{array}{c}\text { Cronología } \\
\text { asociación H-G }\end{array}$ & Bilbiografía \\
\hline Abri Reverdit & $\begin{array}{l}\text { Dordogne- } \\
\text { Francia }\end{array}$ & Abrigo & M & Bajorrelieves & ¿E IV (M)? & Exterior & ¿M? & Roussot $1984 b$ \\
\hline Cap-Blanc & $\begin{array}{l}\text { Dordogne- } \\
\text { Francia }\end{array}$ & Abrigo & M & Bajorrelieves & E IV (M) & Exterior & M & Roussot $1984 \mathrm{c}$ \\
\hline $\begin{array}{l}\text { Grotte de } \\
\text { La Mairie }\end{array}$ & $\begin{array}{l}\text { Dordogne- } \\
\text { Francia }\end{array}$ & Cueva & M & Grabados & E IV (M) & Semiexterior & M & Aujoulat 1984 \\
\hline Grotte Chabot & $\begin{array}{l}\text { Ardèche- } \\
\text { Francia }\end{array}$ & Cueva & S & Grabados & E II-III (G-S) & Semiexterior & S & Combier 1984a \\
\hline Oulen & $\begin{array}{l}\text { Ardèche- } \\
\text { Francia }\end{array}$ & Cueva & G-S-Ep-M & $\begin{array}{l}\text { Pinturas y } \\
\text { grabados }\end{array}$ & E II-III (G-S) & Semiexterior & ¿G-S? & Combier 1984b \\
\hline $\begin{array}{l}\text { Abri de } \\
\text { La Colombiere }\end{array}$ & $\begin{array}{l}\text { Ardèche- } \\
\text { Francia }\end{array}$ & Abrigo & M & Grabados & E IV (M) & Exterior & M & Combier et al. 1984 \\
\hline $\begin{array}{l}\text { Grotte de } \\
\text { Ste. Eulalie }\end{array}$ & Lot-Francia & Cueva & S-M & Grabados & E-IV & Semiexterior & M & $\begin{array}{l}\text { Lorblanchet et al. } \\
1973\end{array}$ \\
\hline Roc-de-Sers & $\begin{array}{l}\text { Charente- } \\
\text { Francia }\end{array}$ & Abrigo & $\mathrm{S}$ & Bajorrelieves & E III (s) & Exterior & S & Tymula 2002 \\
\hline $\begin{array}{l}\text { La } \\
\text { Chaire-à- } \\
\text { Calvin }\end{array}$ & $\begin{array}{l}\text { Charente- } \\
\text { Francia }\end{array}$ & Abrigo & M & Bajorrelieves & E IV (M) & Exterior & M & $\begin{array}{l}\text { Leveque y Vander- } \\
\text { meersch } 1984\end{array}$ \\
\hline $\begin{array}{l}\text { Le } \\
\text { Roc-aux- } \\
\text { Sorciers }\end{array}$ & $\begin{array}{l}\text { Vienne- } \\
\text { Francia }\end{array}$ & Abrigo & M & Bajorrelieves & E IV (M) & Exterior & M & Pinçon 2010 \\
\hline La Roque & $\begin{array}{l}\text { Hèrault- } \\
\text { Francia }\end{array}$ & Cueva & S-M & Grabados & E IV (M) & Semiexterior & M & Lorblanchet 1984 \\
\hline Fumane & Véneto-Italia & Cueva & A & Pintura & E I (A) & Semiexterior & A & Broglio et al. 2009 \\
\hline
\end{tabular}

TABLA I. (continuación)

Pretendemos aquí establecer semejanzas y diferencias entre lo que se ha venido considerando cotidiano y académico, laico o religioso, a partir de una documentación suficientemente indicativa, que no pretende ser exhaustiva, sino útil para el entendimiento de lo que hacían nuestros ancestros.

\section{Espacios de habitación y GRAFÍA}

Como se ha dicho, hace tiempo trabajamos en el concepto espacial de organización interior de las cuevas, en referencia a la posible relación-separación de los espacios utilizados para la representación gráfica y para la llamada vida cotidiana (Balbín-Behrmann y Alcolea-González 1999, 2005) Allí proponíamos la relación que se podía establecer en diversos sitios conocidos del Cantábrico: Altamira, Tito Bustillo, La Garma, La Lluera y La Pasiega. Se trataba de buscar un modelo suficientemente indicativo para poder proponer esas relaciones, fenómeno observado en diversos lugares de referencia. 
Para la propuesta de Breuil (Breuil 1952; Cartailhac y Breuil 1906), organizada como reacción ante las primeras interpretaciones del Arte Paleolítico, éste debía ser producto de la actividad y la conciencia del grupo, cuyo motor no sería el ocio o el disfrute de las formas bellas, sino una ideología que causaría y mantendría las representaciones a lo largo de milenios. En la mente de un sacerdote católico próximo a la Escuela de Viena, esa ideología no podía ser más que la religiosa.

A partir de esta propuesta, plasmación más organizada de una idea ampliamente difundida, la asunción del valor religioso de las representaciones artísticas paleolíticas fue mecánica y universal, extendiendo su valor a todo lo gráfico y rupestre de la Prehistoria. Ese concepto indiscriminado de religión, que incluía de manera acrítica realidades como la magia, el totemismo, el animismo y algunas más, eludía un análisis pormenorizado de las abundantes versiones posibles de creencia, reduciéndolas a un todo unívoco de carácter fuertemente actualista. El mismo Breuil, al tomar las formas representadas como producto religioso, requeriría finalmente la existencia de oficiantes más o menos profesionales para la grafía y un último Dios Supremo, más próximo al cristiano que a los que se documentaban en las encuestas de la Escuela de Viena.

Cuando se propone una idea absoluta de carácter universal sobran los análisis pormenorizados, pero había que hacer más de uno para que la propuesta se sostuviera científicamente, y no se hicieron. ¿Qué relación existiría entre el culto a los ancestros y el Dios Supremo? ¿Qué papel jugarían la magia y el totemismo, cuya función se reconoce en muchos objetos y representaciones? ¿Qué papel jugarían los ritos propiciatorios de la caza, la destrucción y la fertilidad con un Dios Supremo asumido y reconocido? Si los ritos se referían finalmente al ser superior con oficiantes intermediarios, estas acciones deberían realizarse en espacios acondicionados a ese propósito y deberían ser reconocibles para los devotos y para aquellos que venimos después con otras creencias.

La propuesta podía ser muy convincente para los que, como los partícipes de la Escuela de Viena, buscaban el dios originario, para ellos presente en todas las religiones desde las más antiguas. Pero no se trataba de una propuesta bien organizada. Presuponía la asunción de una serie de realidades indemostradas y la idea actualista de un sistema religioso muy lejano a lo pensable para el pasado.

Estas dificultades debían ser reconocibles desde el principio y desmenuzadas por los investigadores posteriores, que ya no sufrían la presión de la autoridad del abate. Este sería el caso de autores de la categoría de Leroi-Gourhan (1971), investigador marxista e independiente que propondría otra interpretación unívoca para el Arte Paleolítico, basada en conceptos cosmológicos de carácter sexual. Su propuesta era distinta y su fundamento aparentemente dispar, pero su realidad final perfectamente comparable. Una vez más el comportamiento gráfico se sustentaba en la religión, única, que organizaba el mundo ideológico en dos mitades compatibles, que al unirse producían y explicaban la realidad. Aquí no se hablaba de un Dios Supremo, pero sí de una Idea Suprema explicativa de todo comportamiento y plasmada en las representaciones gráficas.

Los espacios misteriosos del interior de las cuevas, aquellos reservados para los ritos más importantes, oscuros y sagrados, serían los auténticos templos paleolíticos para Breuil, y el núcleo principal representativo para Leroi-Gourhan, fundamento y meollo de ambas religiones. Quizás la religión de este último fuera más atea, pero no dejaba de ser religión ni de tener sitios especiales para desarrollarse.

Nuestra intención fue la de analizar algunos espacios conocidos y documentados y observar su situación y condición, a ver si reunían las características requeridas para las religiones mistéricas citadas, y nuestra conclusión fue contraria, al comprobar que los sitios decorados que tomábamos como ejemplo, alguno tan emblemático como la propia Altamira, no solo no eran profundos y oscuros, sino que además se encontraban situados en los mismos espacios donde se habitaba, comía, 
dormía, fabricaba y defecaba. Estos eran los casos de Altamira, Tito Bustillo, La Pasiega, La Garma y La Lluera, donde en algunos casos, como La Pasiega y Altamira, el uso de topografías anticuadas e inexactas había conducido a un error de ubicación de los llamados Santuarios Profundos de Leroi-Gourhan (Balbín-Behrmann y Alcolea-González 1999, 29-32).

Se han asumido varias afirmaciones revisables: el carácter sacro de las representaciones artísticas, el carácter profundo y oscuro de los sitios decorados, su apartamiento de los lugares de habitación, el motor religioso único del proceso mental y gráfico paleolítico, y la incapacidad paleolítica de transmitir ideas y vivencias variadas a través de las imágenes. Las revisamos en trabajos anteriores y pretendemos revisarlas ahora bajo otros parámetros (Balbín-Behrmann y Alcolea-González 1999, 2005).

\section{LAS MANIFESTACIONES COTIDIANAS DEL INTERIOR DE LAS CUEVAS}

Ya hemos hablado de la dificultad de diferenciar las acciones humanas en el ámbito cavernario, argumento extensible al aire libre. Es más que posible que los paleolíticos establecieran diferencias de valor entre sus actividades, pero eso no es fácilmente observable en el registro arqueológico. Hemos hablado de las relaciones de lugar entre habitación y representación parietal, y de las que se podrían establecer entre habitación, restos humanos y espacios decorados (Balbín-Behrmann 2015; Balbín-Behrmann y Alcolea-González 1999, 2005). Hemos pretendido con ello organizar significativamente el espacio utilizado en la cueva, intentando valorarlo en relación con su función. Todo parece indicar que el espacio vivido servía para casi todo, sin una valoración preeminente para las funciones de apariencia más importante, léase grafía y enterramiento.

Podemos tomar el ejemplo de Tito Bustillo en su conjunto XI. En su momento entendimos que era exactamente el lugar de entrada antigua de la cueva, pero más tarde averiguamos una entrada algo más lejana, dentro de un bloque desprendido del macizo y separado de él por escasos dos metros, basculado hacia la Gorgocera de entrada del río San Miguel. Dentro de esta boca, acceso auténtico a nuestra cueva en el Paleolítico Superior, no podemos afirmar gran cosa, porque existe una costra estalagmítica que cubre su suelo horizontalmente con una profundidad de al menos setenta centímetros.

Sí podemos sin embargo hablar de la organización de ese conjunto que llamamos XI, en el que desembocaría la antigua entrada recién descubierta y que sería la continuación del acceso natural. Allí excavó un equipo de Alfonso Moure desde el año 1972, en dos sitios diferentes (Moure 1975, 1990; Moure y Cano 1975), el primero situado bajo la arcada que conduce hacia el enterramiento humano, que no arrojó restos arqueológicos. El segundo en un espacio algo al norte, entre la pared y los bloques de caída antigua que conducen hacia el caos interior.

En este último se documentaron dos niveles, pertenecientes en la idea del excavador a un Magdaleniense Superior. En ellos se documentaron varios hogares, abundantes restos líticos y en la zona más próxima al gran bloque septentrional, abundantes objetos decorados. No es el momento de detenerse en la calidad de esos objetos artísticos, pero sí debemos resaltar su ubicación en la misma zona habitada y su fragmentación, producto de un abandono más o menos violento. Todo este espacio que estuvo ocupado durante el Paleolítico Superior final se encuentra próximo a la llamada plazoleta de los bisontes, decorada con pintura, grabado y escultura, y que forma parte de una gran superficie de $50 \times 50 \mathrm{~m}$ con abundantes restos de actividad humana.

No debió ser el único sitio habitado en la cueva, pero aquí se vivía y se fabricaban objetos de diversa condición, también gráfica. Las paredes de este espacio que alcanzan los $35 \mathrm{~m}$ de altura se encuentran decoradas hasta su cúspide y conservan las figuras de mayor tamaño de la cavidad, entre 
ellas bisontes, caballos y cérvidos. Exactamente sobre el espacio excavado en los años setenta aparecen hasta seis discos pintados en rojo (Balbín-Behrmann et al. 2016, fig. 3), comparables a los de otras cuevas, como El Castillo, que a su vez han dado las fechas más antiguas del todo el arte paleolítico hasta el momento (41.400 BP) (Pike et al. 2012, 1410-1411). Son evidentemente más antiguas que los restos materiales excavados a sus pies, que demuestran una presencia finiglaciar pero no anterior. Solo se han documentado aquí actividades en el Magdaleniense avanzado pero eso no significa que la cueva no tuviera una presencia humana más antigua. De hecho las formas gráficas que contiene comienzan con el inicio del Paleolítico Superior, pero no hemos encontrado aún niveles arqueológicos de las épocas más antiguas. Algo podría haber bajo los niveles excavados, en el vestíbulo de entrada recientemente descubierto y en la pendiente que baja hacia la Gorgocera. El futuro nos lo dirá.

Nosotros excavamos en este espacio en los años noventa del pasado siglo, intentando constatar la extensión ocupada en el momento al que pertenecían las excavaciones de Moure. Con ese objeto excavamos en el ángulo norte del espacio, el más lejano posible a aquellas excavaciones dentro del eje occidental de la sala. Allí, y frente a una pequeña cavidad colmatada por el barro y decorada en sus paredes, se veían restos de depósito mezclados con costras calcíticas provenientes del techo. Hicimos un pequeño sondeo de $2 \times 1 \mathrm{~m}$ que ofreció un basurero lleno de desechos de comida, conchas de molusco y huesos animales. En su base mostraba dos huecos de boca paracircular, con su exterior teńido de ocre rojo. Los desechos rebosaban esos primeros contenedores por su parte superior, mezclando el contenido de ambos. Además de los deshechos de comida había restos de talla de útiles líticos, fragmentos de hueso y sílex y placas de hueso y piedra con muestras de decoración, a veces profusa (Balbín-Behrmann y Alcolea-González 2007-2008, 146-148).

Como en el caso de las excavaciones de los años setenta, los materiales decorados habían sido abandonados y en nuestro caso arrojados a los silos-basurero. No parece que eso indique una consideración especial hacia el arte que contuvieran esos objetos, que en algunos casos guardan una similitud importante con ciertas decoraciones parietales de la misma cueva. Los objetos de arte mueble de Tito Bustillo no se conservaron ni veneraron, sino que formaron parte de los desechos de la actividad de sus habitantes.

En esta gran sala que llamamos conjunto XI, se vivió, se pintó, se grabó, se esculpió y se trabajó industrialmente, todo un conjunto de actividades complementarias donde debe incluirse la gráfica, y quizás también otras relacionadas con la cohesión social y la reunión de los grupos que habitaran el macizo de Ardines en esos momentos. El sitio lo permitía y las formas gráficas de las paredes parecen conducir a una contemplación colectiva de grupos numerosos. Tito Bustillo cumple los requerimientos para ser nombrado centro de las actividades sociales de los grupos organizados en el macizo.

El pigmento no parece ser un elemento fundamental para nuestra actividad cotidiana, por más que nos rodea en todo lo que hacemos, habitualmente dotado de color. Su valor, sin embargo, sería diferente en el pasado que estamos tratando, pues se requeriría para la decoración corporal, para el tinte de los vestidos, para el acompańamiento de los muertos y desde luego para la plasmación gráfica. En otros lugares hemos tratado del uso y la obtención de los colorantes de Tito Bustillo, que en síntesis provienen de la parte alta noreste del conjunto XI y se repartieron por toda la cueva, sus pinturas y los miembros del grupo a lo largo de la cuenca del Sella (Balbín-Behrmann 2014, 83-85; Balbín-Behrmann y Alcolea-González 2009, 569-584).

En el conjunto XI se realizaban todas las actividades cotidianas del grupo, incluida la obtención y elaboración de colorantes y la decoración mobiliar y parietal, todas ellas muestras materiales de una actividad muy variada. 


\section{LAS MANIFESTACIONES ARTÍSTICAS CAVERNARIAS A LA LUZ DEL DÍA}

Tanto Laming-Emperaire (1962) como Leroi-Gourhan (1971) hablaron en su momento de las formas gráficas realizadas en las cuevas, pero a la entrada de las mismas, estableciendo lo que llamaron Santuario Exterior, con mayor desarrollo en el caso de Laming-Emperaire. Para el segundo eso significaba un proceso ideológico y cronológico hacia el interior oscuro y religioso de la caverna femenina. Al principio las formas gráficas se producirían en zonas de luz y soporte mueble, para posteriormente introducirse en las de penumbra y soporte rupestre. Finalmente el arte volvería a la luz en el llamado estilo IV Reciente.

La propuesta tenía interés y proponía la apropiación del espacio interior cuando la ideología de los opuestos sexuales había tenido el suficiente desarrollo. La vuelta a la luz supondría el principio del fin del sistema y la ruptura del final de los tiempos fríos. Sin embargo las cosas suelen producirse de manera menos tajante, y los procesos de forma más gradual.

Si analizamos con detenimiento las representaciones muebles de la entrada de las cuevas, veremos que hay muchas más al final del período que al principio, entre otras cosas porque la producción magdaleniense es arrolladora en comparación con las épocas precedentes. Pero también veremos que esas formas muebles se producen tanto al exterior como al interior cavernario, tanto al principio como durante todo el desarrollo del Paleolítico Superior. En conjuntos como Labastide, Enlène, La Garma o Tito Bustillo (Louise y Simonnet 1984; Bégouën et al. 2009; Arias y Ontañón 2012; Arias et al. 1999; Balbín-Behrmann y Alcolea-González 2007-2008) las formas gráficas aparecen en abundancia sobre soporte mueble en el interior y en momentos avanzados y finales del desarrollo gráfico. Lo que podríamos llamar estilo IV Antiguo es rupestre y mueble al interior, del mismo modo que el estilo IV Reciente. No hay traslados topográficos en las representaciones finales del Paleolítico Superior.

¿Y qué ocurre al principio del proceso? Pues aparentemente lo mismo. Es cierto que en yacimientos como La Lluera (Fortea 1989), Santo Adriano (Fortea 2005) o Chufín (Almagro-Basch 1973) las formas gráficas aparecen al exterior, casi al aire libre. Pero también es cierto que en el mismo Chufín elementos similares a los exteriores aparecen pintados al interior en la misma época antigua, o que los paneles primeros de La Garma se encuentran precisamente al interior de la misma, más allá incluso que aquellos que pertenecen a momentos recientes (González-Sainz 2003, 220-221). En otras cuevas, como Tito Bustillo, es precisamente en los sitios más profundos donde se obtienen restos de actividad gráfica más antigua, como es el caso de la Galería de los Antropomorfos (Balbín-Behrmann et al. 2016, 11, fig. 7). Lo mismo puede decirse de El Castillo y de su Galería de los Discos (D’Errico et al. 2016). Según los sitios, el arte se plasma al interior y al exterior, al principio y al final del proceso. Quizás haya un hecho diferencial que dificulte la conservación de la pintura en zonas exteriores, pero eso es todo. El fenómeno no se produce siempre, como tampoco todas las cuevas están decoradas, pero es suficientemente frecuente para invalidar la tesis del proceso gráfico hacia el interior que propuso Leroi-Gourhan.

Se actúa gráficamente dentro y fuera, pero ¿dónde se vive? La tradición científica habla de una vivienda en zonas externas, para aprovechar la luz natural, la posible insolación, la aireación correspondiente y la proximidad a las actividades cotidianas exteriores. Pero eso no se produce siempre (tabla 1), sino que tiene excepciones, probablemente más abundantes si se hubiera investigado en el interior de muchos yacimientos. Cuando esto se ha hecho, las constataciones de habitación y uso profundo cavernario son abundantes. Así lo hemos comprobado en la cueva de Tito Bustillo, donde los restos de frecuentación y actividad en los lugares alejados de la entrada son abundantes, y eso a pesar de la destrucción definitiva del ambiente original ocasionada por la adaptación para 
la entrada turística (Balbín-Behrmann y Alcolea-González 2003). Otro caso paradigmático es el de La Garma donde los restos de habitación llegan hasta sus profundidades, a $100 \mathrm{~m}$ de la antigua entrada, hoy cegada (Arias y Ontańón 2012; Arias et al. 1999). El hecho de esta sorprendente conservación nos ha permitido constatar algo que debió ser frecuente, y es que las cuevas eran habitadas y decoradas al exterior y al interior en todas las épocas, en proximidad, sin espacios diferenciales, en perfecta convivencia y uso compartido.

\section{Las CUevas Al AIRE Libre}

En el apartado anterior hemos hablado de los espacios decorados cavernarios que se encuentran próximos a la luz natural, y que aparecen en todas las épocas, como pasa en Altamira, Tito Bustillo, La Pasiega (Balbín-Behrmann y Alcolea-González 1999) y tantos otros sitios en momentos avanzados del ciclo artístico paleolítico. Hemos hablado también de cuevas donde existe una decoración exterior, casi al aire libre.

Hace ya tiempo acuñamos el nombre de cuevas al aire libre para hablar de aquellos sitios decorados en época paleolítica que se encontraban a la intemperie, lejos de cualquier concepto de ocultación u oscuridad. Esa es su condición definitoria, pero hay otra igualmente importante que es la de su organización igual a la de las cuevas. Recorridos, conjuntos, paneles, objetos y sistemas son semejantes a los interiores, pero se producen al exterior absoluto. Se trata de auténticas cuevas al aire libre.

Los yacimientos aparecen en espacios dominantes del paisaje, con una evidente función de control a distancia de los acontecimientos, o bien en vados y riberas fluviales, por donde pasaría todo el mundo, cuando no se vivía directamente allí. Este es el caso de todos los yacimientos de la frontera hispano-portuguesa (Balbín-Behrmann 2008), de los castellanos, andaluces o catalano-franceses. Siega Verde (Alcolea-González y Balbín-Behrmann 2006) se propuso en su momento como modelo de esa conducta y el modelo sigue vigente.

En origen era difícil fechar esas manifestaciones artísticas, por falta de contexto material arqueológico y de elementos de datación directa fiables. Nosotros (Balbín-Behrmann y Alcolea-González 2001, 2002) hicimos una propuesta basándonos en el ahora tan denostado sistema cronoestilístico de Leroi-Gourhan, y esa propuesta se demostró acertada a pesar de los detractores que hubo al principio (Baptista 2001). Se demostró acertada porque finalmente pudo aplicarse la metodología arqueológica en las excavaciones de Fariseu de las márgenes del río Côa.

Allí el equipo franco-portugués comandado por Thierry Aubry procedió a excavar un habitáculo situado a nivel del río actual, liberado de agua por la bajada del embalse de Pozinho en el río Duero, del que depende el nivel del Côa. Ese habitáculo es un espacio limitado en su lado norte por una pared decorada con los grabados del tipo mayoritario en la zona, que se realizaron desde un suelo utilizado en el Gravetiense. Se trataba de un sitio de habitación, ocupado a lo largo de todo el Paleolítico Superior hasta la transición al Holoceno, con esa pared septentrional y abundantes placas decoradas en sus niveles superiores, indicativas de esa transición gradual y discreta hacia tiempos modernos (Aubry y Sampaio 2008).

La excelente excavación demostró no solamente que las formas gráficas más antiguas debían remontarse al menos hasta el estilo II de Leroi como habíamos propuesto nosotros, sino que además el arte rupestre y el mueble convivían en el mismo espacio de vivienda a lo largo de todo el Paleolítico Superior. Era además el primer gran argumento arqueológico material para datar todo el arte al aire libre, aunque la cronología estilística ya se había establecido. 
El arte paleolítico al aire libre es hermano gemelo del cavernario, se hace en el mismo momento y tiene los mismos protagonistas. Tiene como diferencia exclusiva el soporte, habitualmente esquisto, pero los mismos estilos y técnicas, con una mayor abundancia de grabados piqueteados que deriva de la condición de la roca. Como el cavernario se hace en el sitio donde se vive y transita, y dura todo el Paleolítico Superior, con desarrollos finales en el tránsito hacia el postpaleolítico. Carece de oscuridad y misterio y muestra un modo de comunicación generalizado en la época que podría contener todo aquello que el grupo deseara comunicar, incluyendo conceptos cosmo-teleológicos que desconocemos.

Hay ocasiones, como ocurre en Molino Manzánez (Collado 2009, 290-295, fig. 10), en que se graban con línea incisa figuras como la de un bisonte, cuya capacidad de visualización actual es escasa, por lo fino de su línea y por el tamaño total de la figura. En esos casos es lícito pensar que la línea de contorno serviría como esbozo de algo más complejo que incluiría la pintura. Pero eso ocurre también con los grabados piqueteados, de mejor visualización siempre, pero muy probablemente acompañados de pintura para resaltar su apariencia, como se documenta en otros lugares más afortunados en su conservación como Siega Verde (Balbín-Behrmann y Alcolea-González 2009, 585-588) o Faia (Baptista 2008, 73). Por ejemplo la Roca 13 de Ribeira de Piscos (fig. 2) (Baptista 2008, 74-75), un gran panel sobre el río Côa que se eleva a más de diez metros sobre éste, contiene tres grandes figuras de uro piqueteadas en su contorno que se pueden observar desde el otro lado del río. Si a su apariencia actual añadiéramos el color de la pintura, se trataría de auténticas llamadas en la distancia. Muy cerca de estos bóvidos se encuentra el yacimiento de Fariseu, único excavado hasta el momento que demuestra la compañía de grabados parietales y viviendas. $\mathrm{Su}$ excepcionalidad actual no significa que ésta fuera así en el pasado. Es lícito pensar que los lugares de ocupación humana en las proximidades de los grabados fuera habitual, como además de Fa-

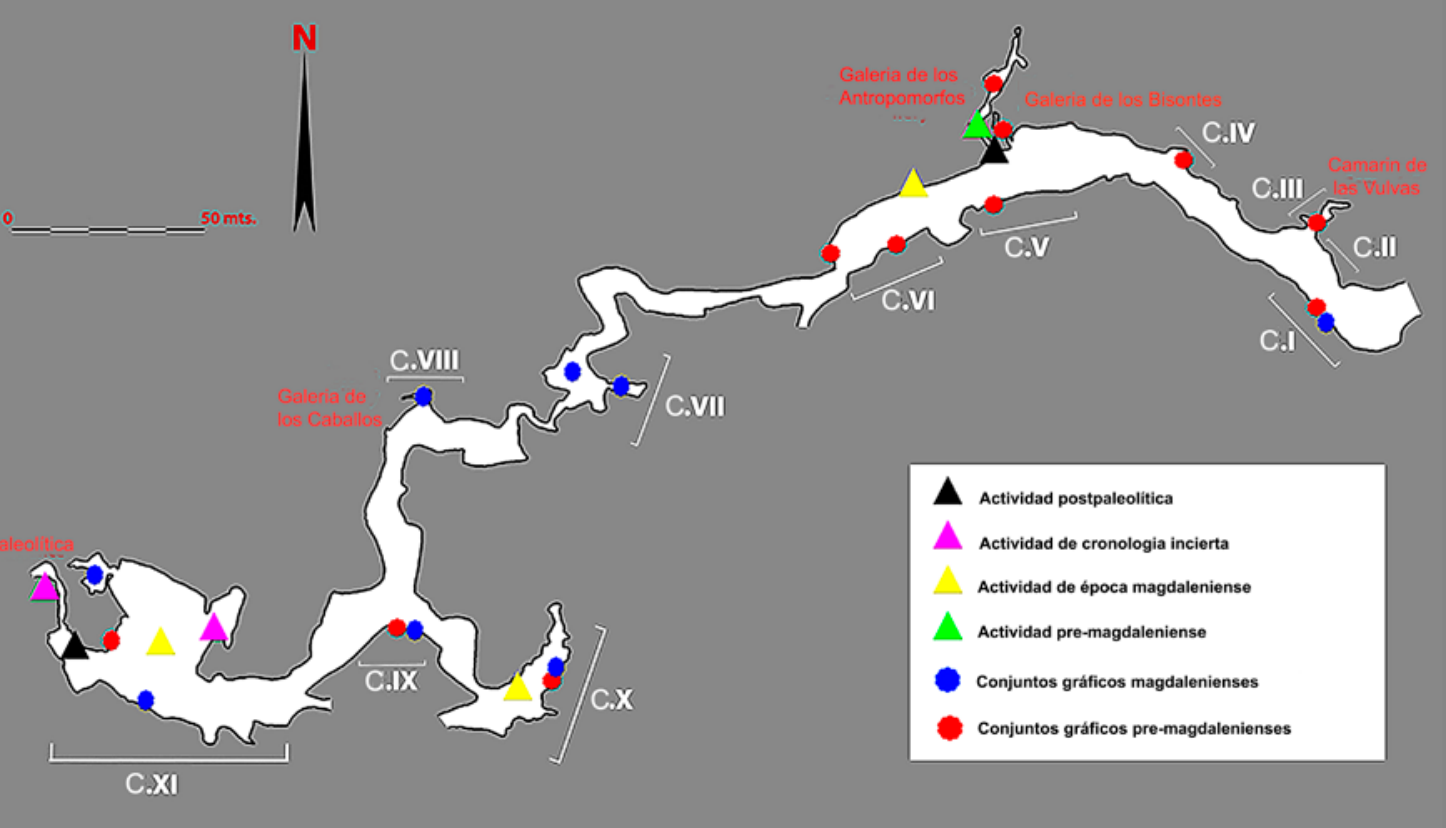

Figura i. Plano de la cueva de Tito Bustillo con indicación de sus conjuntos 
riseu demuestran los yacimientos de Cardina, en el meandro que antecede al conjunto de Quinta da Barca (Aubry y Sampaio 2008).

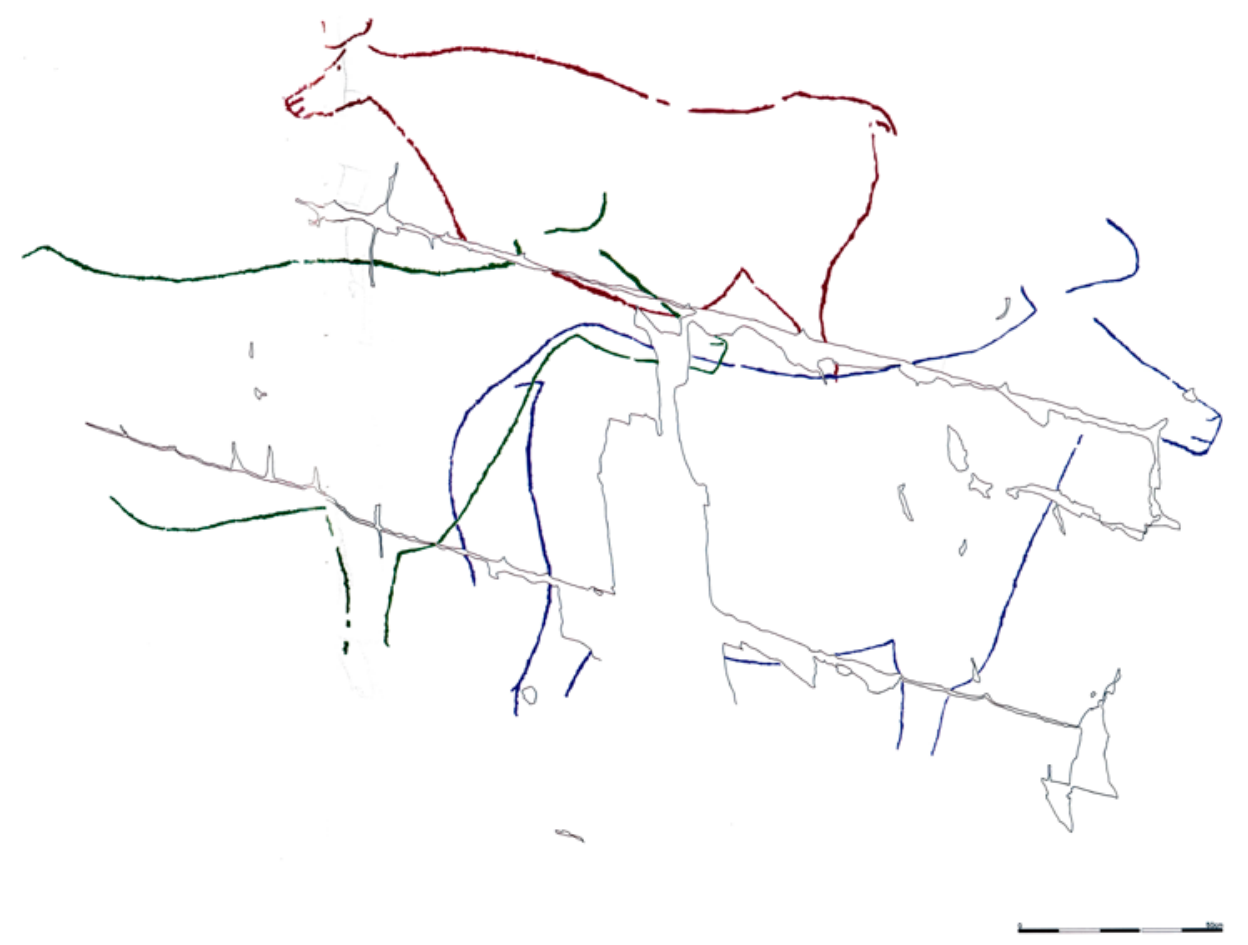

Figura 2. Calco de los grandes uros de Ribeira de Piscos según Baptista 2008 fig. 75

\section{REFLEXIÓN FINAL}

Hemos propuesto referencias indicativas del comportamiento humano y gráfico fuera y dentro de las cuevas en el Paleolítico Superior, indicando continuidad de unas y otras manifestaciones, sin sitios especializados para aquello que se entiende como religioso, el Arte Rupestre. Se vive y se decora en los mismos sitios a lo largo de todo el tiempo.

La falta de lugares especializados en el Paleolítico Superior se demuestra también en otro comportamiento seleccionado como es el enterramiento, cuyas parcas manifestaciones en la Península Ibérica aparecen de nuevo en los lugares de comportamiento común (Balbín-Behrmann 2015). Este es un hecho que ya se había podido considerar a la luz de lo conocido en el interior cavernario, donde la forma mueble del arte se encontraba en los mismos niveles de los yacimientos vividos, pero es aún más patente ahora a partir del descubrimiento del Arte Rupestre Paleolítico a la intemperie, donde no se dan los parámetros escondidos propios de lo que se afirmaba para su hermano subterráneo.

No son iguales todos los yacimientos en cueva o al aire libre. Entre los primeros los hay que permiten la reunión de muchas personas en actitud relacionante, y también los que permiten una 
escasa presencia humana, pero en todos los casos las formas gráficas acompañan el espacio y el comportamiento comunes.

Lo mismo se podría decir del arte exterior absoluto, donde hemos comprobado la compañía vivienda-arte en sitios como Fariseu, y poco más, dada la escasez de trabajos relativos a esa comprobación (Aubry y Sampaio 2008; Aubry et al. 2010; Garcia-Diez y Aubry 2002; Balbín-Behrmann 2015) pero sí sabemos que las formas gráficas formaban parte de lo cotidiano, en el transcurso por el paisaje, donde los grupos humanos dejaban muestra de sí y de su espacio psicológico.

Pero todo esto no se produjo una vez, en los albores de la conducta gráfica del Paleolítico Superior, sino que continuó en el tiempo hasta su definitivo colapso al final de la Protohistoria. Los sitios tradicionales (Bueno 2009; Bueno et al. 2007, 2009) vivieron a lo largo de muchos milenios y siguieron teniendo valor conmemorativo y expresivo para las gentes que siguieron ocupándolos durante el decurso de la Prehistoria que nos hemos empeñado en parcelar y denominar de maneras diversas. Así ocurre en la zona aragonesa de la Fuente del Trucho, en la levantina de la Valltorta y Cieza, en la andaluza de la cueva de Ambrosio o del Campo de Gibraltar, en la extremeña del Tajo, Cheles o Santiago de Alcántara, en la portuguesa del Côa o de la Foz do Medal, y en la castellana de Domingo García (Balbín-Behrmann 2008). Los espacios significativos pervivieron en el tiempo conservando su valor de libro escrito para las generaciones futuras.

No creemos que las representaciones gráficas carezcan de contenido ideológico o mítico, pero sí creemos que reducir todo su significado al ámbito religioso es una simpleza esquemática que anula todas las demás capacidades de comunicación inherentes al acto. También pensamos que esas ideas teleológicas posibles en el pasado prehistórico no guardan una relación suficiente con lo que hoy entendemos por religión y que ha sido entendido con ese actualismo en la crítica científica hasta la actualidad. Ideas sí, pero diferentes a la religión contemporánea. El vehículo gráfico es susceptible de contener significados y comunicaciones varias, desde luego más que las puramente creenciales. Las ideas del grupo fueron indudablemente variadas y su vehículo gráfico también, acompañante cordial del resto de las actividades materiales del conjunto humano.

\section{BiBLIOGRAFÍA}

Alcolea-González, J.J., Balbín-Behrmann, R. De, 2006, "Arte Paleolítico al aire libre. El yacimiento rupestre de Siega Verde, Salamanca», Arqueología de Castilla y León 16, Valladolid: Junta de Castilla y León.

Almagro-Basch, M. 1973, "Las pinturas y grabados rupestres de la cueva de Chufín, Riclones (Santander)", Trabajos de Prehistoria 30, 1-44.

Arias, P., Ontañón, R. 2012, "La Garma (Spain): Long-Term Human Activity in a Karst System», en: K.A. Bergsvik, Skeates, R., Caves in Context (eds.), The Cultural Significance of Caves and Rock shelters in Europe, Oxford: Oxbow Books, 101-117.

Arias, P., González-Sainz, C., Moure, J.A., Ontañón, R. 1999, La Garma un descenso al pasado, Santander: Gobierno de Cantabria/Universidad de Cantabria.

Aubry, T., Sampaio, J.D. 2008, "Chronologie et contexte archéologique des gravures paléolithiques de plein air de la Vallée du Côa (Portugal)» en: R. de Balbín-Behrmann (ed.), Arte Prehistórico al aire libre en el Sur de Europa, Salamanca: Junta de Castilla y León, 209-221.

Aubry, T., Dimuccio, L.A., Bergadè, M., Sampaio, J.D., Sellami, F., 2010, «Palaeolithic engravings and sedimentary environments in the Côa River Valley (Portugal): implications for the detection, interpretation and dating of open-air rock art», Journal of Archaeological Science 37 (2010) 3306-3319. 
Balbín-Behrmann, R. De, 2008, «El Arte Rupestre Paleolítico al aire libre en la Península Ibérica», en: R. de Balbín-Behrmann (ed.), Arte Prehistórico al aire libre en el Sur de Europa, Salamanca: Junta de Castilla y León, 17-54.

—, 2014, "Los caminos más antiguos de la imagen: el Sella», en: M.A. de Blas-Cortina (ed.), Expresión simbólica y territorial: los cursos fluviales y el arte paleolitico en Asturias, Oviedo: Real Instituto de Estudios Asturianos, 65-91.

—, 2015, "Death in the cave. Human remains from the Upper Palaeolithic in the Iberian Peninsula», en: L. Rocha, Bueno-Ramírez, P., Branco, G. (eds.), Death as Archaeology of Transition: Throughts and Materials, BAR International Series 2708, 1-28.

Balbín-Behrmann, R. de, Alcolea-González, J.J. 1999, "Vie quotidienne et vie religieuse. Les sanctuaires dans l'art paléolithique», L'Anthropologie 103-1, 23-50.

—, 2001, «L'Art Paléolithique en plein air dans la Péninsule Ibérique: quelques précision sur son contenu, chronologie et signification ", en: J. Zilhao, Aubry, T, Carvalho, A.F. (eds.) Les premiers hommes modernes de la Péninsule Ibérique. Actes du Colloque de la Commission VIII de la U. I. S. P. P., Trabalhos de Arqueología 17, 205-236.

—, 2002, "L'Art. Rupestre Paléolithique de la Meseta. Une vision chrono-culturelle d'ensemble», en: D. Sacchi (dir.), L'art. Paléolithique à l'air libre. Le paysage modifié par l'image, Carcassonne: GAEP\&GEOPRE, 139-157.

—, 2005, «Espace d'habitation, espace d'enterrement, espace graphique. Les coïncidences et les divergences dans l'art paléolithique de la corniche cantabrique», en: D. Vialou, Renault-Miskowsky, J., Pathou-Mathis, M.E. (eds.), Comportements des hommes du Paléolithique moyen et supérieur en Europe: territoires et milieux, ERAUL 111, 193-206.

—, 2007-2008, «Arte mueble en Tito Bustillo: los últimos trabajos», Homenaje a Ignacio Barandiarán, Veleia 24-25, 131-159.

—, 2009, «Les colorants de l'art paléolithique dans les grottes et en plein air», L'Anthropologie 113, 559-601.

Balbín-Behrmann, R. de, Alcolea-González, J.J., Alcaraz-Castaño, M. 2016, "The Palaeolithic art of Tito Bustillo cave (Asturias, Spain) in its archaeological context», Quaternary International (2016), http://dx.doi.org/10.1016/j.quaint.2016.01

Balbín-Behrmann, R. de, Alcolea-González, J.J., González-Pereda, M.A. 2003, «El Macizo de Ardines, un lugar mayor del arte paleolítico europeo», en: R. de Balbín-Behrmann, Bueno-Ramírez, P. (eds.), El Arte Prehistórico desde los inicios del siglo XXI. Actas del Primer Symposium Internacional de Arte Prehistórico de Ribadesella, Ribadesella: Asociación Cultural Amigos de Ribadesella, 91-151.

—, 2005, «La Lloseta: une grotte importante et presque méconnue dans l'ensemble d'Ardines, Ribadesella», L'Anthropologie 109, 641-701

Balbín-Behrmann, R. de, Bueno-Ramírez, P., Alcolea-González, J.J., Barroso, R., Aldecoa, A., Giles, F., Finlayson, C., Santiago, A., 2000, "The engravings and Palaeolithic paintings from Gorham's Cave», en: C. Finlayson., Finlayson, G., Fa, D. (eds.), Gibraltar during the Quaternary. The southernmost part of Europe in the last two millions years, Gibraltar: Gibraltar Government Heritage Publications [Monographs 1], 179-195.

Balbín-Behrmann, R. DE, González-Sainz, C., 1993, «Nuevas investigaciones en la cueva de La Pasiega (Puente Viesgo, Cantabria)», Boletín del Seminario de Estudios de Arte y Arqueología LIX, 9-38.

Baptista, A.M., 2001, "The Quaternary Roc Arte of the Côa Valley (Portugal)», en: Les prémiers hommes modernes de la Péninsule Ibérique. Actes du Colloque de la Commision VIII de la UISPP, Lisboa: Instituto Português de Arqueologia, 237-252.

—, 2008, O vale do Côa e a Arte paleolítica de ar livre em Portugal, Vila Nova de Foz-Côa/Porto: Parque Arqueológico do Vale do Côa.

Bégouën, R., Fritz, C., Tosello, G., Clottes, J., Pastoors, A., Faist, F., 2009, Le sanctuaire secret des Bisons. Il y a 14000 ans, l'art et la vie dans la caverne du Tuc d'Audoubert, Paris: Editions d'art Somogy/ Association Louis Bégouën.

Breuil, H., 1952, Quatre cents siècles d'art pariétal, Paris: Editions Max Fourny. 
Bueno-Ramírez, P., 2009, «Espacios decorados al aire libre del occidente peninsular. Territorios tradicionales de cazadores recolectores y de productores», en: R. de Balbín-Behrmann (ed.), Arte Prehistórico al aire libre en el Sur de Europa, Salamanca: Junta de Castilla y León, 321-344

Bueno-Ramírez, P., Balbín-Behrmann, R. DE, 2009, «Marcadores gráficos y territorios tradicionales en la Prehistoria de la Península Ibérica», Cuadernos de Prehistoria y Arqueología de la Universidad de Granada 19, 65-100.

Bueno-Ramírez, P., Balbín-Behrmann, R. de, Alcolea-González, J.J., 2007, "Style V dans le bassin du Douro. Tradition et changement dans les graphies des chasseurs du Paléolithique Supérieur européen ", L'Anthropologie 111, 549-589.

Cartailhac, E, Breuil, H., 1906, La caverne d'Altamira à Santillane près de Santander (Espagne), Imprimerie de Monaco.

Collado, H., 2009, «Arte rupestre prehistórico en Extremadura. 1997-2006», en: R. de Balbín-Behrmann (ed.), Arte Prehistórico al aire libre en el Sur de Europa, Salamanca: Junta de Castilla y León, 287-322.

Corchón, M.S., González-Aguilera, D., Muñoz, A. L., Gómez, J., Herrero, J. S., 2009, «Documentación, modelado y reconstrucción 3D de la cueva de Las Caldas (Asturias, España). El yacimiento y el Arte parietal», Excavaciones Arqueológicas en Asturias 6, 355-366.

D’Errico, F., Dayet, L., García-Diez, M., Pitarch, A., Garrido, D., Zilhao, J., 2016, «The technology of the earliest European cave paintings: El Castillo Cave, Spain», Journal of Archaeological Science 70, 48-65.

Fortea, J., 1989, «Cuevas de La Lluera. Avance al estudio de sus artes parietales», en: M.R. González-Morales (ed.), Cien años después de Sautuola. Estudios en Homenaje a Marcelino Sanz de Sautuola en el Centenario de su muerte, Santander: Diputación Regional de Cantabria, 187-202.

—, 2005, "Los grabados exteriores de Santo Adriano (Tuñón. Santo Adriano. Asturias)», Homenaje a Jesús Altuna, Munibe 57, 23-52.

GonzÁlez-SAInZ, C., 2003, «El conjunto parietal de la Galería inferior de La Garma (Cantabria). Avance a su organización interna», en: R. de Balbín-Behrmann, Bueno-Ramírez, P. (eds.), El Arte Prehistórico desde los inicios del siglo XXI. Actas del Primer Symposium Internacional de Arte Prehistórico de Ribadesella, Ribadesella: Asociación Cultural Amigos de Ribadesella, 201-222.

García Diez, M., Aubry, Th., 2002, "Grafismo mueble en el valle de Côa (Vila Nova de Foz Côa,Portugal): la estación arqueológica de Fariseu", Zephyrus LV, 157-182.

Laming-Emperaire, A., 1962, La signification de l'art rupestre paléolithique: Méthodes et applications, Paris: Imprimerie Picard et Cie.

Leroi-Gourhan, A. 1971, Préhistoire de l'art occidental, Paris : Mazenod.

Louise, G., Simonnet, R., 1984, "Grotte de Labastide», en: L'art des Cavernes, Atlas des grottes ornées paléolithiques françaises. Paris: Imprimerie National, 527-35.

Moure, J.A., 1975, Excavaciones en la cueva de Tito Bustillo (Asturias): Campañas de 1972 y 1974, Oviedo: Publicaciones del Instituto de Estudios Asturianos.

—, 1990, "La cueva de Tito Bustillo (Ribadesella, Asturias): el yacimiento paleolítico», Excavaciones Arqueológicas en Asturias 1, 1983-86, 107-127.

Moure, J.A., Cano, M., 1975, Excavaciones en la cueva de Tito Bustillo (Asturias): Trabajos de 1975, Oviedo: Publicaciones del Instituto de Estudios Asturianos

Pike, A.G.W., Hoffmann, D.L., García-Diez, M., Pettitt, P.B., Alcolea-González, J.J., BalbínBehrmann, R. de, González-Sainz, C., Heras, C. de las, lasheras, J.A., Montes, R., Zilhao, J., 2012, "U-Series Dating of Palaeolithic Art in 11 Caves of Spain», Science 336, 1409-1413.

Rodríguez Asensio, J.A., Barrera Logares, J.M., 2012, «La Lluera II (San Juan de Priorio. Oviedo. Asturias. España). Estudio integral de un santuario complementario solutrense», Espacio, Tiempo y Forma, serie I. Nueva Época. Prehistoria y Arqueología, 5: 87-108.

—, 2014, El arte de la frontera: Cien años del descubrimiento de la caverna de la Peña de Candamo, Excavaciones Arqueológicas en Asturias. Monografías, 2, Oviedo: Consejería de Cultura. 